Бочарніков В. П., д.т.н., професор (ORCID 0000-0003-4398-5551)

Центр воєнно-стратегічних досліджень Національного університету оборони України імені Івана Черняховського, Київ

\title{
Частотно-часовий аналіз сигналів на основі функцій поведінки і арифметичних рядів. Частина 1. Аналіз підходів, опис методу.
}

Резюме. У статті пропонується новий підхід до частотно-часового аналізу дискретних сигналів, які представлені часовими рядами. Для опису значень часового ряду використовується базис $p$-адичних чисел, на основі яких будуються функції поведінки системи. Аналіз даних функцій дає змогу провести ідентифікацію метасистем і побудувати імпульсні функції, що формалізують часовий ряд. Координати імпульсів описуються арифметичними рядами, які використовуються для оцінювання частотного спектру сигналу.

Ключові слова: часовий ряд; частотно-часовий аналіз; р-адичні числа; функції поведінки систем; системний аналіз; ідентифікація; арифметичні ряди; частотні спектри.

Вступ. Матеріальним носієм інформації щодо стану об'єктів є сигнали, класифікація яких досить повно розглянута в роботі [1]. Як правило, на сьогодні, на підставі теореми відліків [2, 3] сигнали представляються в дискретному вигляді. У цьому випадку впорядкована послідовність результатів вимірювань сигналу, зафіксованих в послідовні моменти часу, прийнято називати часовим рядом. Можна виділити три основні завдання, які вирішуються під час аналізу часових рядів [4]:

1. Визначення кількісних характеристик процесу, який породив цей часовий ряд, в тому числі частотно-часових характеристик сигналу, його енергії та інші;

2. Декомпозиція часового ряду на елементарні складові для подальшого вивчення їх кількісних характеристик;

3. Кількісне порівняння часових рядів для виявлення подібностей і відмінностей між процесами, якими вони породжені.

Під час вирішення цих завдань для обробки сигналів застосовуються як просторово-часові, так і частотні інструменти обробки сигналів [5]. Як показала практика, будь-який просторово-часовий сигнал може бути описаний сукупністю базисних функцій [6]. Це дає змогу отримати спектр сигналу. Він відображає частку вмісту цих базисних функцій у вихідному сигналі. Таке розкладання часто виявляється досить корисним для аналізу сигналів. Наприклад, спектральне представлення сигналу виявляється краще, ніж його просторовочасове представлення в разі аналізу стисливості сигналів і синтезу алгоритмів стиснення 3 мінімальними втратами. Спектральна обробка сигналу може бути корисна під час розв'язання задачі фільтрації сигналів, розпізнаванні образів тощо.

Аналіз існуючих підходів. Перехід до спектру може здійснюватися з використанням ортогональних i унітарних перетворень. Найбільш часто для отримання спектру використовується розкладання по ортогональних функціях [7]. Наприклад, спектри, отримані на основі розкладання в ряд Фур'є [8] (у разі гармонійного базису), ряд Уолша [9] (у разі використання негармонійної ортогональної системи прямокутних функцій зі значеннями \pm 1$)$, вейвлет-перетворення $[10,11]$ тощо. У всякому разі розкладання вихідної неперервної функції $\varphi(t)$ на ортогональні функції може бути представлено у вигляді:

$$
\varphi(t)=\sum_{k=0}^{\infty} c_{k} \times \Phi(k, t),
$$

де $\quad c_{k}=\int_{0}^{T}[\varphi(t) \times \Phi(k, t)] d t-$ коефіцієнти розкладання, $\Phi(k, t)$ - система базисних ортогональних функцій. До того ж неперервної функції $\varphi(t)$ відповідатиме дискретний (лінійчатий) спектр 3 коефіцієнтами $c_{k}$. У дискретному випадку функція відліків $\varphi_{n}$ має вигляд:

$$
\varphi_{n}=\sum_{k=0}^{N-1} c_{k} \cdot \Phi_{k_{s} n^{\prime}}
$$

$c_{k}=\sum_{n=0}^{N-1} \varphi_{n} \times \Phi_{k, n} \quad-\quad$ коефіцієнти розкладання, $\Phi_{k, n}$ - ортогональна система дискретних функцій.

Найважливішим питанням у випадку розкладання функції $\varphi(t)$ по ортогональному базису залишається вибір раціональної системи 
$\Phi(k, t)$. Вирішення цього питання залежить від поставленого завдання [12]. Так під час аналізу і синтезу сигналів, що впливають на лінійні ланцюги, найбільшого поширення набула система гармонійних функцій, яка традиційно розглядається в радіотехніці. Під час розв'язання задачі наближеного розкладання складних сигналів 3 необхідною точністю при мінімумі членів ряду для представлення безперервних сигналів застосовуються поліноми і функції Лагерра, Лежандра, Чебишева, Ерміта тощо. Для представлення сигналів 3 точками розриву використовуються кусково-постійні функції Уолша, Хаара, Радемахера. Для дискретизації безперервних сигналів у часі використовується ортогональний ряд Котельникова. Останніми роками для аналізу часових рядів широко використовуються базисні функції типу вейвлетів.

Найбільш широке розповсюдження отримав класичний підхід на основі прямого та зворотного перетворення Фур'є. Ці перетворення $\epsilon$ хорошим інструментом для вивчення стаціонарних процесів. Перетворення Фур'є забезпечує відображення в точку інформації про періодичність функції у процесі переходу 3 часової області в частотну. Досягається це через те, що функція $e^{-i 2 \pi \omega t}$, яка $\epsilon$ ядром перетворення Фур' $\epsilon$, не локалізована в часі, але має граничну локалізацію в частотної області. Водночас саме ця властивість зумовлює недоліки Фур'єперетворення, зокрема:

1. Перетворення Фур'є дає інформацію про зміст кожної частоти в сигналі, але не дає змоги визначити момент часу виникнення $\mathrm{i}$ закінчення цієї частоти.

2. Обмежена інформативність аналізу нестаціонарних сигналів і практично повна відсутність можливостей аналізу сигналів за наявності в них сингулярності (розривів, сходинок, піків і т.п.) у силу представлення особливостей сигналів на всьому спектрі. 3'являються “паразитні” високочастотні складові, які явно відсутні у вихідному сигналі за наявності в ньому сингулярності.

3. Гармонійні базисні функції розкладання не здатні відображати перепади сигналів із нескінченної крутизною (прямокутні імпульси), оскільки для цього потрібна нескінченно велика кількість членів ряду. В іншому випадку в районі стрибків $\mathrm{i}$ розривів у разі відновлення сигналу виникають осциляції (явище Гіббса).

4. Перетворення Фур’є відображає глобальні відомості про частоти сигналу і не дає уявлення про локальні властивості сигналу за швидких тимчасових змін його спектрального складу. Так, наприклад, перетворення Фур'є не розрізняє стаціонарний сигнал, утворений сумою двох синусоїд, від нестаціонарного сигналу, утвореного двома синусоїдами 3 тими ж частотами, які йдуть послідовно. Перетворення Фур'є не має можливості аналізувати частотні характеристики сигналу в довільні моменти часу.

5. Використовуючи перетворення Фур'є, можна працювати із сигналом або тільки в часі, або тільки в частотної області. Одночасно отримати частотно-часове представлення сигналу за допомогою класичного алгоритму перетворення Фур'є неможна.

Таким чином, перетворення Фур'є забезпечує ефективний аналіз стаціонарних часових рядів у частотної області. Однак результати застосування до реальних часових рядів відомих критеріїв, що дають змогу перевірити статистичну гіпотезу про стаціонарність ряду (наприклад, AFD-тест ДікіФуллера [13], KPSS-тест Квятковські-ФілліпсаШмідта-Шина [14]) показують, що більшість 3 них виявляється нестаціонарними. Серед відомих методів аналізу нестаціонарних часових рядів слід зазначити метод миттєвого спектра [15] (Д. Габор, Дж. Вілль тощо.), вейвлет-перетворення [16] (I. Добеши, I. Мейер, Р. Коіфман тощо.), Метод сингулярного спектрального аналізу на основі перетворення Карунена-Лоева [17], інші підходи, які наведені в огляді [18]. Однак, як показує аналіз досвіду їх використання, кожен 3 них виявляється не вільним від власних недоліків. Це виявляється, зокрема, в тому, що під час аналізу часових рядів через використання згорток виявляються складові, існування яких суперечить фізичним уявленням про механізми, що породжують цей часовий ряд.

Останнім часом широкого поширення набули підходи до аналізу часових рядів на основі вейвлет перетворень [19]. Незважаючи на досить високу ефективність вейвлет-аналізу нестаціонарних часових рядів, як показала практика, є низка складнощів у їх використанні. Зокрема у разі використання вейвлетперетворень необхідно враховувати ряд спотворень [20]:

1. Амплітудні спотворення, обумовлені істотним придушенням у смузі пропускання від середньої частоти до частот зрізу і помітне пропускання гармонік у смузі затримання. 
2. Гіперболічні спотворення, обумовлені тим, що смуга пропускання змінюється нелінійно через зміни масштабу вейвлетів. До того ж ця нелінійність змінюється за гіперболічним законом. Через це результати вейвлет-перетворення за різних масштабів стають непорівнянними.

3. Спотворення через перекриття смуг, які пов'язані 3 тим, що смуги пропускання мають перекриття від 50 до 95\%. Це породжує додаткові кореляції в частотно-часової області.

4. Спотворення перетворення до шкал частот у процесі побудови скейлограм, які призводять до стискання низьких частот $\mathrm{i}$ розтягуванню високих частот. Крім цього під час використання квадратичних, нелінійних перетворень спостерігаються амплітудні спотворення, що підвищують амплітуди високих частот і знижують амплітуди середніх і низьких частот.

Для мінімізації спотворень потрібно, перш за все, обгрунтований вибір виду вейвлета, який багато в чому залежить від характеру тимчасового ряду. Цим вибором можна впливати на розрізнювальну здатність результату за часом i за частотою, що зумовлюе значну вільність в отриманні вихідного результату вейвлет-аналізу. Наприклад, використання вейвлета Морлі [21] забезпечує насамперед високу розрізнювальну здатність в частотної області, а використання вейвлета Похідна Гауссіана [22] (DOG) призводить до гарної локалізації за часом, але поганої локалізації за частотою.

Таким чином, використання для спектрального розкладання сигналу системи ортогональних функцій на основі згорток функцій призводить до спотворень і помилок в оцінці спектра. Якість отриманих результатів безпосередньо залежить від правильного вибору відповідних параметрів методу (типу використаного базисного вейвлета, розміру вікна аналізу, масштабу, вибору функції вікна для спектрограми тощо). Це призводить до необхідності використання для кожного часового ряду, який аналізується, апріорної інформації, що найчастіше складно.

Для подолання цього недоліку в 1998 р. Н. Хуангом був запропонований свій метод аналізу часових рядів (Huang-Hilbert Transform - HНT) [23]. Він передбачає використання адаптивного базису, який автоматично підлаштовується під поточним часом ряд. В основі підходу лежить емпірична модова декомпозиція і перетворення Гілберта [24]. Було показано, що будь-який часовий ряд може бути представлений у вигляді адитивної суміші базисних компонент (мод) i залишкового ряду. Набір мод може представлятися не ортогональними функціями, він не фіксований, $є$ адаптивним і залежить тільки від виду вихідних даних. Підхід має високу наочність, відносну простоту і показав хорошу ефективність, що визначило його зростаючу популярність у дослідників. Однак він також не позбавлений недоліків. Підхід має проблеми вибору сплайнів для декомпозиції сигналу, критерію зупинки при відсіюванні залишку, набору значущих мод і їх змішування, проблеми крайових ефектів при перетворенні Гілберта і емпіричної декомпозиції [25]. За допомогою цього підходу скрутним $\epsilon$ представлення частотно-часової локалізації тимчасового ряду, який досліджується.

Таким чином, аналіз існуючих підходів до частотно-часового аналізу часових рядів показав, що, незважаючи на їх хорошу теоретичну i математичну проробку, широке практичне застосування проблема аналізу часових рядів залишається актуальною. Використання в якості міри схожості в алгоритмах розкладання вихідних функцій по базисних функціях операцій згортки призводить до природних спотворень спектрів, появи артефактів у разі наявності сингулярності у вихідних функціях, впливу крайових умов для обраних вікон обробки сигналу. Крім цього залишається досить складним вибір параметрів алгоритмів спектрального аналізу (вибір функції вікна, типу вейвлета тощо). Спроба використання альтернативного підходу, що базується на розкладанні часового ряду по базисних функціях, які спеціально згенеровані i адаптивні до цього ряду, також мають недоліки. До того ж природа цих недоліків лежить у деякій вільності визначення базисних мод у розкладанні сигналу. Виділення базисних мод недостатньо враховують внутрішню структуру нестаціонарної поведінки системи, яка генерує досліджуваний сигнал. Таким чином, розроблення нових підходів, які 3 одного боку будуть досить прості у застосуванні, а з іншого боку до певної міри враховуватимуть недоліки існуючих підходів залишається актуальною.

Метою статті $\epsilon$ висвітлення альтернативного підхіду до аналізу часових рядів, який, деякою мірою, не матиме ключових недоліків Фур'є аналізу, матиме переваги вейвлет-перетворень, але через це буде простіше їх в реалізації і враховуватиме 
нестаціонарну поведінку системи, що генерує досліджуваний сигнал.

\section{Виклад основного матеріалу}

Представлення часових рядів на основі функиій поведінки систем та імпульсних функцій. Аналіз підходів до частотно-часового перетворення нестаціонарних часових рядів показав, що для забезпечення зниження впливу спотворень обраної сітки частотночасової локалізації сигналу необхідно врахувати поведінку системи, яка генерує досліджуваний сигнал. Слід розуміти, що стабільне поведінка системи буде характеризуватися порівняно стабільним частотним спектром. Зміна спектра сигналу відбувається, перш за все, під час зміни поведінки системи.

Для визначення поведінки системи скористаємося підходом до системного аналізу на основі функцій поведінки [26]. Нехай $A_{i}$-множина проявів виділеної властивості досліджуваного об'єкта, що породжує сигнал, а $B$-множина проявів базової властивості часового ряду (час спостереження сигналу). Конкретний прояв властивості $a_{i} \in A_{i}$ формалізується змінною $v_{i} \in V_{i}$ за допомогою каналу спостереження виду $o_{i}: A_{i} \rightarrow V_{i}$ [27]. Для конкретного прояву базової властивості (моменту часу) $b \in B$, яке формалізується значенням параметра $t \in W$, значення змінної $v_{i} \in V_{i}$ визначатиме стан сигналу. Відповідно до теореми відліків, дані, що представляють сигнал, носять дискретний характер часового ряду i можуть бути формалізовані у вигляді матриці розмірності $V \times W$ (рис. 1), яка задає систему даних $D$, де $V=V_{1} \times V_{2} \times \cdots \times V_{n}, n$ - кількість виділених властивостей системи. Елементом цієї матриці буде значення змінної $v_{i, t}=d_{i}(t) \in V_{i}$, де $d(t): W \rightarrow V_{i} \quad$ функція, яка ставить у відповідність будь-якому параметру системи його повний стан змінних. Слід зазначити, що в разі використання нечіткого каналу спостереження [28] елементом матриці буде розподіл впевненості на множині значень змінної $\mu_{t}\left(v_{i}\right): W \times V_{i} \rightarrow[0,1]$.

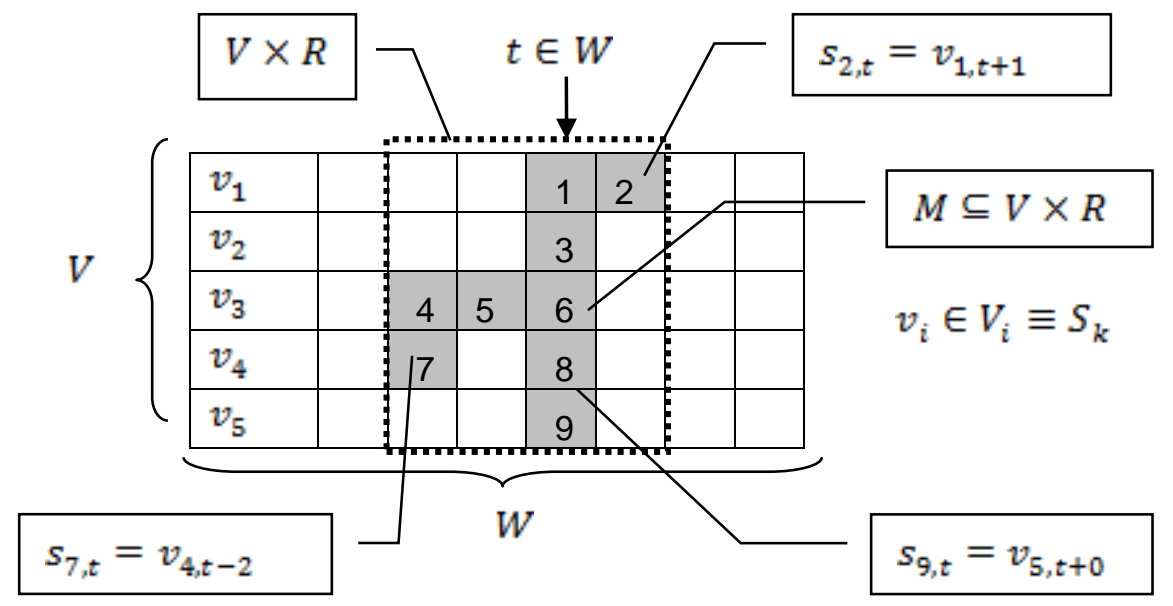

Рис. 1. Матриця чітких даних системи, визначення вибіркових змінних і маски

Для поточного значення параметра $t \in W$ крім стану системи $v_{i, t} \in V_{i}$ можна виділити додаткові змінні, які задаються відображенням правила зсуву у вигляді $\zeta: W \rightarrow W$. Для часового ряду у разі повністю впорядкованій множині $W$ правило зсуву задається функцією: $\zeta(t)=t+\rho$, де $\rho \in Z$ ціле число. Тоді стан системи для множини змінних системи $V$ визначається вибірковими змінними, які задаються співвідношенням $s_{k_{z} t}=v_{i_{2} r_{k}(t)} \in V_{i} \equiv S_{k}$, де $s_{k, t}-$ стан $k$-й вибіркової змінної при параметрі $t \in W$, $v_{i, r_{k}}(t) \in V_{i}-$ стан змінної $v_{i} \in V_{i}$ при значенні параметра $\zeta_{k}(t)=t+\rho_{k}, \rho_{k} \in Z$. Приклад визначення вибіркових змінних наведений на рис. 1.

Для фіксованого параметра $t \in W$ поточний стан системи $c(t) \in C$ визначатиметься підмножиною маски системи $M \subseteq V \times R$, де $R=\left\{\zeta_{k}\right\}-$ множина всіх правил зсуву, а повний стан системи задаватися декартових добутком $C=S_{1} \times S_{2} \times \cdots \times S_{|M|}$, де $|M|-$ потужність маски $M$.

Значення сигналу в дискретний момент $t \in W$ при квантуванні за рівнем [29] 
описується цілим числом $b(t) \in Z_{t s} \subseteq Z$, де $Z_{t s}$ - множина можливих значень часового ряду. Без порушення спільності міркувань можемо вважати $Z_{t s} \subseteq N$, де $N$ - множина натуральних чисел, $\min \left\{Z_{t s}\right\}=0$, а $\max$ $\max \left\{Z_{t s}\right\}=b_{\max } \in N$. Будь-яке натуральне число $b(t)$ може бути представлено у вигляді цілого $p$-адичного числа виду [30]:

$$
b(t)=\sum_{l=0}^{L} \alpha_{l} \times p^{l},
$$

де $p>1$ - натуральне просте число, $\alpha_{l}=\{0, \ldots, p-1\}, \quad l=\{0, \ldots, L\}-$ рівень ієрархії, необхідний для представлення числа $b(t)$ у вигляді $p$-адичного числа. Тоді всі можливі значення часового ряду утворюють кільце $Z_{p}$ цілих $p$-адичних чисел. 3 огляду на це представлення ціле $p$-адичне число однозначно визначається канонічної формою [31] у вигляді послідовності $b(t)=\left\{\alpha_{0}, \alpha_{1}, \ldots, \alpha_{l_{2}}, \ldots, \alpha_{L}\right\}, \quad$ де $\alpha_{l}=\{0, \ldots, p-1\}-$ цілі позитивні числа. Це представлення однозначно визначає значення часового ряду при кожному $t \in W$.

Нехай значення змінної системи $v_{i} \in V_{i}$, визначається на множині станів $V_{i}=\left\{v_{i 1}, \ldots, v_{i, L+1}\right\}$, де $v_{i j}=\alpha_{l+1}, j=l+1, \quad l=\overline{0, L} . \quad$ Тоді $\quad$ стан системи за даною змінною для $t \in W$ визначається функцією розподілу впевненості $\mu_{t}\left(v_{i, j}\right): W \times V_{i} \rightarrow[0,1]$, яка задається на основі $p$-адичного числа $b(t)$ у вигляді:

$$
\mu_{t}\left(v_{i j}\right)=\alpha_{l+1}(t) \cdot\left(\max _{l=0, L} \alpha_{l}(t)\right)^{-1},
$$

де $\alpha_{l}(t)$ - значення $l$-го елемента канонічної форми $p$-адичного числа. Цей підхід дає змогу побудувати нечіткі канали спостереження змінних $o_{i}: A_{i} \rightarrow V_{i} \quad 3$ сюрьективним відображенням (рис. 2). Для уточнення поведінки системи, що визначає часовий ряд, стан системи може бути додатково описаний вибірковими змінними 3 використанням правила зсуву $\forall k, \rho_{k} \neq 0$.

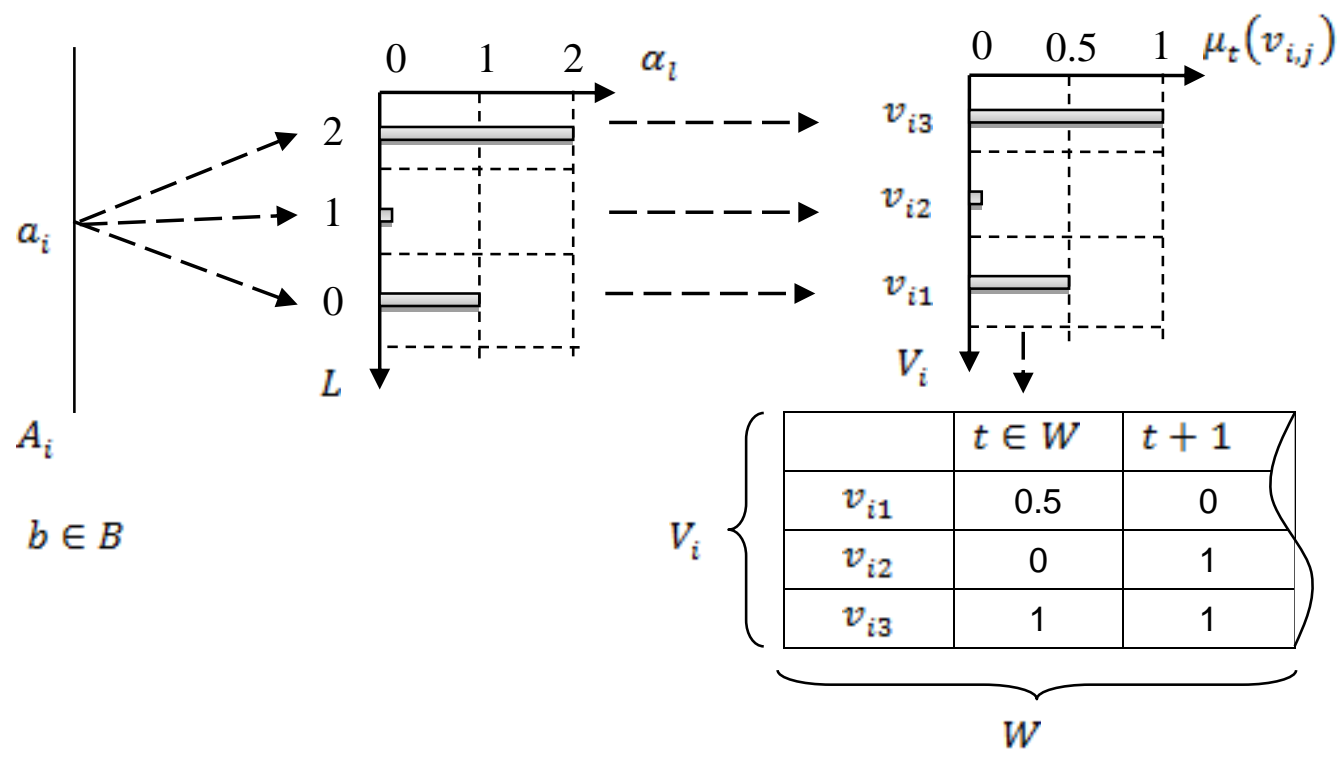

Рис. 2. Нечіткий канал спостереження стану часового ряду на основі $p$-адичних чисел при $p=3$

Таким чином, повна множина станів вибіркових змінних системи, що описують часовий ряд, визначається декартовим добутком виду $C=S_{1} \times S_{2} \times \cdots \times S_{[M]}$. Для нечіткого каналу спостереження при фіксованому значенні параметра $t \in W$ кожному стану вибіркової змінної $s_{k}$ буде відповідати $\mu_{t}\left(s_{k, j}\right)=\mu_{r_{k}(t)}\left(v_{i, j}\right) \in[0,1]$.
Для стану системи $c \in C$ конкретна вибіркова змінна $s_{k}$ приймає значення $s_{k}[c] \in S_{k} \equiv V_{i} . \quad$ Відтак, спостереження цього стану за цією змінною в момент часу $t \in W$ буде $\mu_{t}\left(s_{k}[c]\right)$. Тоді в цілому можливість появи стану системи $c \in C$ в даний момент буде визначатися як

$$
f_{t}(c)=\min _{k=\overline{1}_{l}|M|}\left\{\mu_{t}\left(s_{k}[c]\right)\right\} .
$$


Зважаючи на це, можливість спостереження стану $c \in C$ на інтервалі параметра $\Delta W \subseteq W$ може бути оцінена співвідношенням:

$$
f(c)=\left\{\sum_{t \in \Delta W} f_{t}(c)\right\} \cdot\left\{\max _{\in \in C} \sum_{t \in \Delta W} f_{t}(e)\right\}^{-1} .
$$$$
\text { Функція } f(c): C \rightarrow[0,1] \text { є функцією }
$$

поведінки системи. Вона визначає ступінь впевненості в появі стану $c \in C$ системи на інтервалі $\Delta W \subseteq W \quad \epsilon \quad$ параметричним інваріантним обмеженням на множині станів вибіркових змінних. Ця функція дає змогу ефективно описати реальну поведінку системи. Аналіз цієї функції відкриває можливість отримання значущої інформації про поведінку системи, що генерує часовий ряд станів.

Раніше вказувалося, що зміна частотного спектра часового ряду відбувається за умови зміні поведінки системи. Системи зі змінною поведінкою найбільш повно описуються у вигляді метасистем, для яких інтегрування локальних систем 3 поведінкою, заданих на своїх параметричних множинах $\Delta W_{m} \subseteq W, m \in N_{W}$, здійснюється на основі процедури заміни [32] $q: W \rightarrow \mathscr{F}$, де $\mathscr{F}-$ множина всіх локальних систем 3 поведінкою.

Ключовим питанням $\epsilon$ визначення областей локальної однорідності поведінки системи на множині $W$, що передбачає ідентифікацію процедури заміни. Для повністю упорядкованої параметричної множини $W$ ідентифікація функції q базується на системних властивостях зміни показника породжуючої нечіткості системи [33] для заданої функції поведінки. Ций показник для нечітких систем 3 поведінкою, що породжують часової ряд, розраховується за формулою:

$$
U(f(c))=\sum_{j=1}^{\|c\|}\left(f\left(c_{j}\right)-f\left(c_{j+1}\right)\right) \cdot \log _{2}(j),
$$

Крок 5. Якщо

$$
\left|U\left(f_{k}(c)\right)-U\left(f_{k-1}(c)\right)\right| / \max
$$

то виконується перехід на Крок 3. Якщо умова не виконується, то точка $t+(k-1) \times m \in W$ приймається як апроксимація точки заміни елементів метасістеми. Для цієї точки де $f(c)$ - впорядкована по спаданню $\forall j, f\left(c_{j}\right) \geq f\left(c_{j+1}\right)$ функція поведінки 3 фіктивним елементом $f\left(c_{|c|+1}\right)=0$.

Дослідження систем [34] показали:

1. Якщо на інтервалі параметра $[0, t]$ немає істотної зміни локальних обмежень на породження даних, то із зростанням $t \in W$ породжуюча нечіткість системи швидко сходиться до рівня менше деякого порога $\Delta$.

До того ж при малих значеннях $t$ може спостерігатися перехідний процес;

2. Якщо на деякому інтервалі параметра $\left[t_{1}, t_{2}\right] \epsilon$ локальне обмеження, то всередині інтервалу параметра $\left[t_{1}, t_{2}\right]$ породжуюча нечіткість буде менше порога $\Delta$, а в точках $t_{1}$ i $t_{2}$ вона буде зростати i перевищуватиме поріг $\Delta$.

Якщо в системі спостерігаються суттєві коливання породжуючої нечіткості, то така система має бути представлена у вигляді метасистеми. До того ж ідентифікація функції $q$ здійснюється за алгоритмом:

Крок. 1. Задаються параметри алгоритму ідентифікації: ціле число $m>1$ i поріг $\Delta$. На першому кроці приймаються початкові умови для параметра $t=1 \mathrm{i}$ коефіцієнта алгоритму $k=1$.

Крок 2. Для підмножини даних $[t, t+m]$ визначаються функція поведінки $f_{1}(c)$ і значення показника породжуючої нечіткості системи $U\left(f_{1}(c)\right)$.

Крок 3. Здається $k=k+1$. Якщо $t+k \times m \notin W$, то виконується перехід на крок 6.

Крок 4. Визначається функція поведінки $f_{k}(c)$ для підмножини даних $[t, t+k \cdot m] \subseteq W \quad$ і $\quad$ визначається породжуюча нечіткість $U\left(f_{k}(c)\right)$.

$\left(U\left(f_{k}(c)\right), U\left(f_{k-1}(c)\right)\right)<\Delta$,

приймається значення $k=1$ і виконується перехід на Крок 2.

Крок 6. Стоп. 
Якщо вважати, що в моменти часу зміни поведінки системи формується одиничний імпульс, то поведінка довільного часового ряду для фіксованого порога $\Delta_{u} \in[0,1], u=\overline{1, N_{\triangle}} \quad$ для дискретних моментів $t \in W$ може бути описана у вигляді імпульсної функції (рис. 3):

$$
r(u, t)=\left\{\begin{array}{l}
1, t=\tau_{n} \\
0, t \neq \tau_{n} .
\end{array}\right.
$$

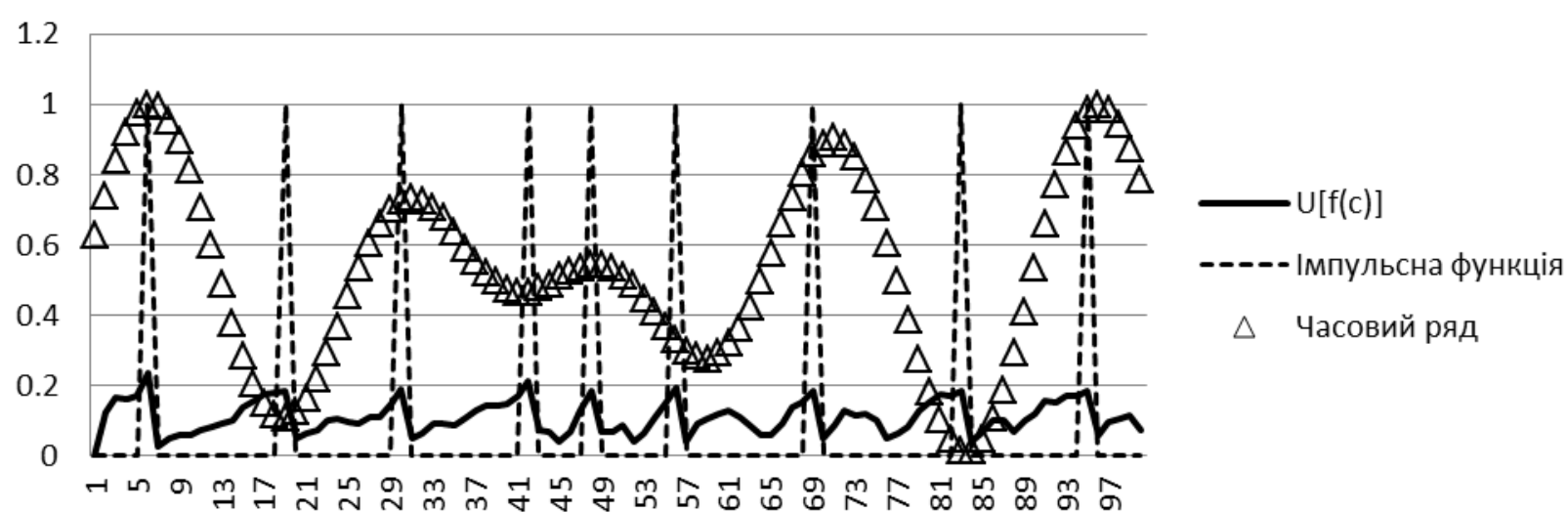

Рис. 3. Зміна показника нечіткості та імпульсна функція для метасистеми, яка описус нормований часовий ряд. Функція поведінки визначена для $p=2,|M|=7, \Delta=0.18$

Координати імпульсів $\tau_{n} \in W$ визначатимуться точками, які отримані на основі алгоритму ідентифікації метасистем, i відповідати членам арифметичного ряду:

$$
\tau_{n}=\tau_{1}+\sum_{j=2}^{n} d(j)
$$

де $\tau_{n} \in W-n$-й член ряду, що задає часову координату $n$-го імпульсу, $d(j)$ - змінний крок ряду, що визначає інтервали стабільної поведінки досліджуваного часового ряду.

Аналіз імпульсних функцій для різних часових рядів (у тому числі нестаціонарних) показав високу стійкість послідовності імпульсів і їх чітку відповідність поведінці системи. Поява імпульсів залежить від обраного порога $\Delta_{u} \in[0,1]$. До того ж, чим більше поріг, тим менше утворюється імпульсів, що відповідає зниженню рівня чутливості до зміни поведінки системи. Крім цього імпульсна функція залежить від обраних параметрів дискретизації часового ряду i алгоритму ідентифікації метасистеми (числа $m>1)$, які вносять деяку похибку у визначенні точок зміни поведінки метасистеми. Узагальнена імпульсна функція (рис. 4), що враховує множину порогів $\left\{\Delta_{u}\right\}$ на дискретному часовому просторі $W$ для довільного часового ряду може бути визначена у вигляді функції:

$$
g(t)=\sum_{\Delta_{u} \in\{\Delta\}} \Delta_{u} \cdot r(u, t),
$$

де $r(u, t)$ - імпульсна функція для порога $\Delta_{u}$ алгоритму ідентифікації.

$$
\text { Тоді часові координати } \tau_{n} \in W
$$

апроксимуючої імпульсної функції $r(t)$ для довільного часового ряду можуть бути визначені як точки локальних максимумів функції $g(t)$ (рис. 4). До того ж координати $\tau_{n}$ підкорятимуться правилу числової послідовності зі змінним кроком $d(j)$.

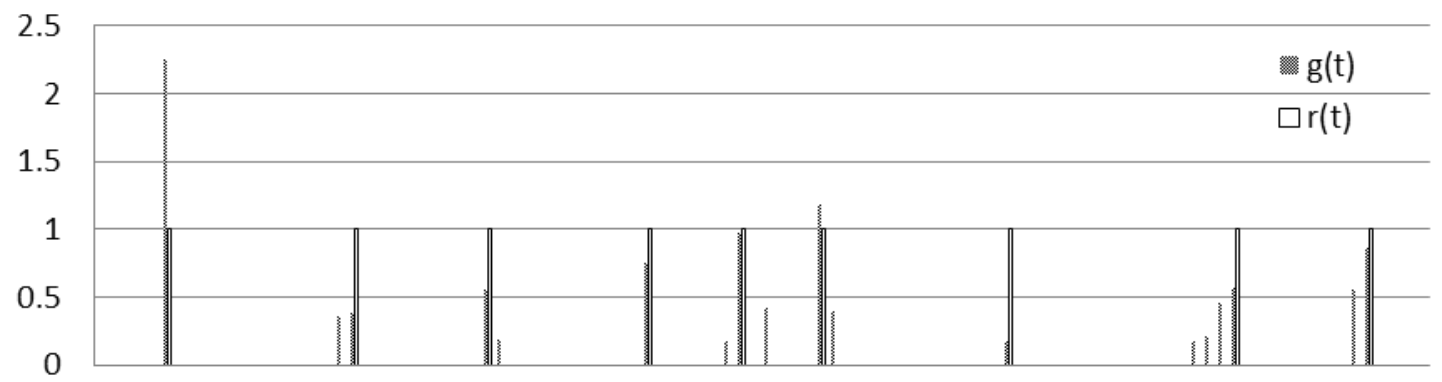

$\begin{array}{lllllllllllllllllllllllll}1 & 5 & 9 & 13 & 17 & 21 & 25 & 29 & 33 & 37 & 41 & 45 & 49 & 53 & 57 & 61 & 65 & 69 & 73 & 77 & 81 & 85 & 89 & 93 & 97\end{array}$

Рис. 4. Апроксимація імпульсної функції довільного часового ряду 
Аналіз імпульсних функцій для періодичних часових рядів, наприклад синусоїдальних (рис. 5), показав, що часові координати імпульсів відповідних імпульсних функцій підкоряються правилам арифметичних прогресій виду:

$$
a_{m}^{k}=a_{1}^{k}+(m-1) \times d_{k^{\prime}}
$$

де $a_{m}^{k} \in W, k$ - індекс $k$-ї синусоїди, $d_{k}=$ const - крок арифметичній прогресії.

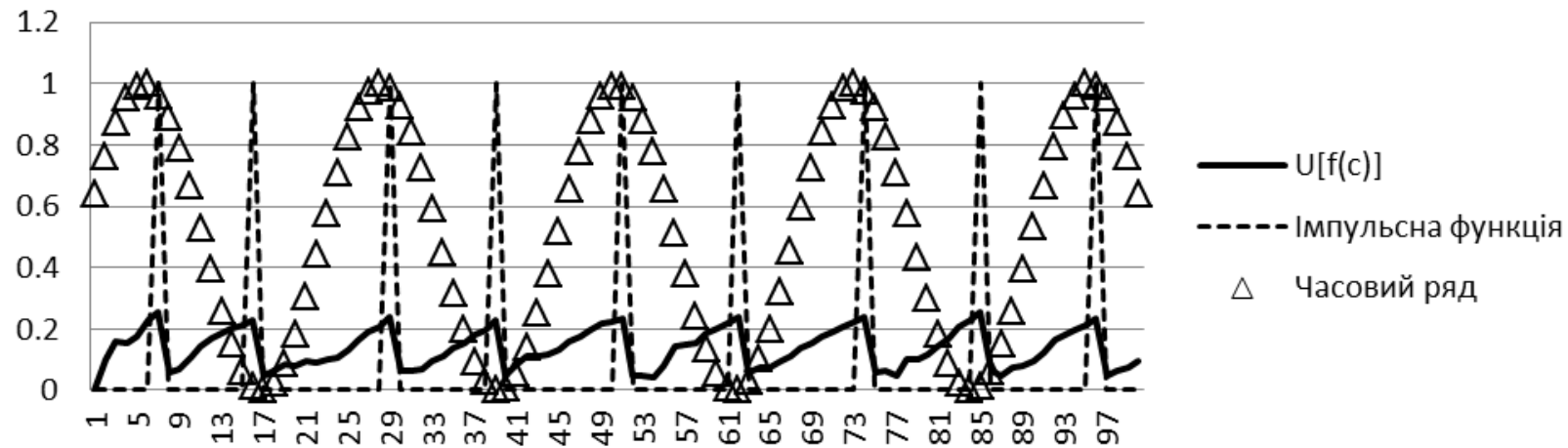

Рис. 5. Імпульсна функція для синусоїдального часового ряду

Проте змінні арифметичної прогресії, які описують синусоїду, чітко визначають іiі фазово-частотні параметри. Зокрема $a_{1}^{k}$ відповідає фазовому зсуву, а $d_{k}-$ половині періоду $k$-ї синусоїди. Імпульсну функцію 3 характеристиками, що задовольняють співвідношенню арифметичної прогресії, називатиме імпульсним синусом, i позначатиме $s i_{k}(t), t \in W$. Для конкретизації параметрів імпульсного синуса може використуватися запис у вигляді $s i_{k}\left(t \mid a_{1}^{k}, d_{k}\right)$.

Постановка задачі. Таким чином, 3 огляду на властивості отриманих імпульсних функцій, виникає питання про можливість використання функцій $s i_{k}(t)$ для спектрального аналізу нестаціонарних часових рядів $\varphi_{n}$, поведінка яких описується відповідної імпульсної функцією. Задача зводиться до визначення залежності появи імпульсів досліджуваного часового ряду в координатах $\tau \_n$ від функцій імпульсних синусів, тобто $\tau_{n}=\mathbb{F}\left(x_{k}, s i_{k}(t)\right), \quad$ де $x_{k} \in[0,1]-$ ступінь прояву $k$-ї функції імпульсного синуса. Таке розкладання однозначно дасть змогу визначити спектральні характеристики довільного часового ряду, а також розв'язати задачу його відновлення.

Підхід до частотно-часового аналізу часових рядів на основі арифметичних прогресій. Під час досліджень була виявлена логіка взаємодії арифметичних рядів, що моделюють процеси. Для довільного часового ряду, утвореного сумою синусоїдальних функцій, було встановлено, що зміна поведінки системи, яка породжує імпульс в точці $\tau_{n}$, відбувається, коли результуючий висхідна (спадна) поведінка ряду змінюється на спадну (висхідну) поведінку відповідно. До того ж в областях ліворуч і праворуч від точки $\tau_{n}$ існує баланс протилежних напрямів поведінки ряду. Для прикладу тимчасового ряду утвореного двома синусоїдами розподіл імпульсних функцій наведено на рис. 6 .

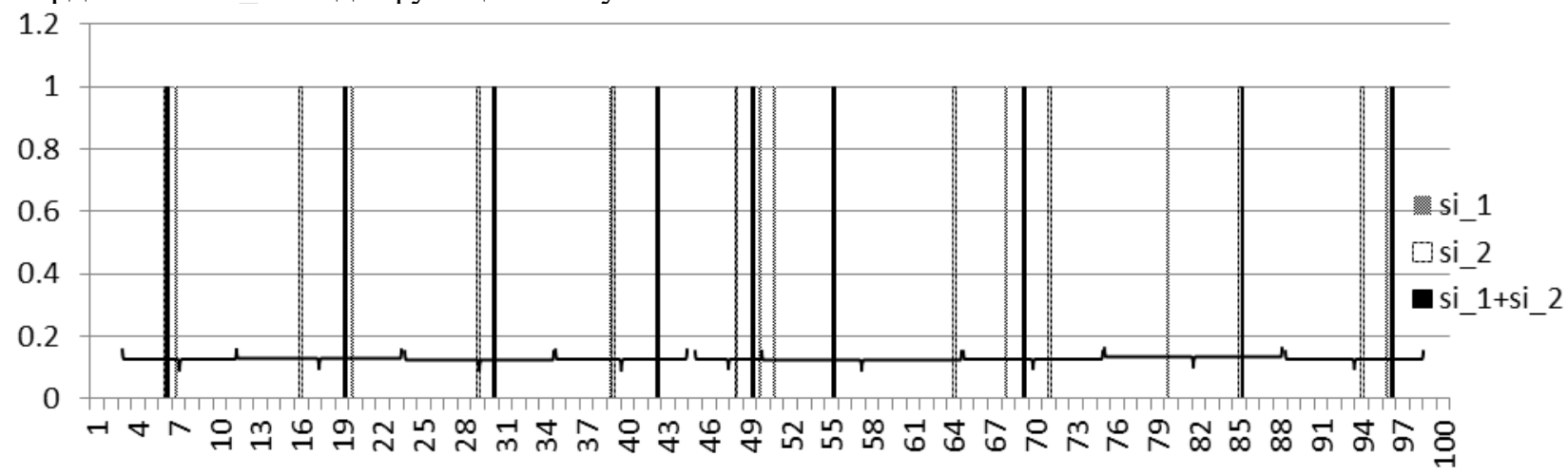

Рис. 6. Взасмодія імпульсних функцій 
На появу імпульсу результуючої імпульсної функції $r(t)$ в точці $\tau_{n} \in W$ впливають імпульси функцій $s i_{k}(t)$, які потрапляють в деяке активне вікно навколо точки $\tau_{n}$ (дужки на рис. 6), подобласть $L \subseteq W$ ліворуч і подобласть $R \subseteq W$ праворуч від точки $\tau_{n}$. Для функції імпульсного синуса $s i_{k}(t)$ характерно те, що для непарних значень $m_{k}$ в області, де $t<a_{m}^{k}$ спостерігається висхідна поведінка синусного часового ряду, а для області, де $t>a_{m}^{k}$ відповідно спадна поведінка. Для парних значень $m_{k}$ ситуація змінюється на протилежну.

3 огляду на цю властивість імпульсних синусів, вплив одного імпульсу в координаті $a_{m}^{k} \in W$ функції $s i_{k}(t)$ на формування поведінки результуючого часового ряду для області $L \subseteq W$ визначатиметься значенням: $\operatorname{Vol}_{L}\left[s i_{k}\left(a_{m}^{k}\right)\right]=$

$$
=(-1)^{m-1} \times s i_{k}\left(a_{m}^{k}\right) \times\left(\tau_{n}-a_{m}^{k}\right) \text {, }
$$

де значення $(-1)^{m-1}$ враховує напрямок поведінки синусної функції.

Аналогічно для області $R \subseteq W$ вплив визначатиметься значенням: $\operatorname{Vol}_{R}\left[s i_{k}\left(a_{m}^{k}\right)\right]=$ $=(-1)^{m} \times s i_{k}\left(a_{m}^{k}\right) \times\left(a_{m}^{k}-\tau_{n}\right)$.

У випадку, коли до області $L \subseteq W$ потрапляє більше одного імпульсу функції $s i_{k}(t)$, вплив цієї функції на формування імпульсу $r\left(\tau_{n}\right)$ знижується. Вплив цього фактора для одного імпульсного синуса в області $L \subseteq W \quad$ визначатиметься співвідношенням:

$$
\operatorname{Vol}_{L}\left[\operatorname{si}_{k}(x)\right]=\sum_{a_{m}^{k} \in L} \operatorname{Vol}_{R}\left[s i_{k}\left(a_{m}^{k}\right)\right]=\sum_{a_{m}^{k} \in L}(-1)^{m-1} \cdot\left(\tau_{n}-a_{m}^{k}\right)
$$

Аналогічно визначається вплив функції одного імпульсного синуса в області $R \subseteq W$ у вигляді значення:

$$
\begin{array}{cc}
\operatorname{Vol}_{R}\left[s i_{k}(x)\right]=\sum_{a_{m}^{k} \in R}(-1)^{m} \times\left(a_{m}^{k}-\tau_{n}\right)=\sum_{a_{m}^{k} \in R}(-1)^{m-1} \times\left(\tau_{n}-a_{m}^{k}\right) . \\
\text { Для появи імпульсу функції } r\left(\tau_{n}\right) \text { має } \quad \operatorname{Vol}_{L}\left[s i_{k}(x)\right]=-\operatorname{Vol}_{R}\left[s i_{k}(x)\right] .
\end{array}
$$
виконуватися умова балансу зміни поведінки для областей $L$ i $R$ навколо точки $\tau_{n} \in W$. Цей баланс для функції $k$-го імпульсного синуса формується за умови:

$$
\sum_{a_{m}^{k} \in L \cup R \subseteq W}^{k}(-1)^{m-1} \times\left(\tau_{n}-a_{m}^{k}\right)=\sum_{a_{m}^{k} \in L \cup R \subseteq W}(-1)^{m-1} \cdot \tau_{n}-\sum_{a_{m}^{k} \in L \cup R \subseteq W}(-1)^{m-1} \times a_{m}^{k}=0 .
$$

У цьому рівнянні коефіціснт $\beta_{k}=\sum_{a_{m}^{k} \in L \cup R}(-1)^{m-1}$ приймає значення в множині $\{-1,0,1\}$. Другий доданок виразу $\epsilon$ частковою сумою знакозмінного числового ряду, отриманого 3 арифметичної прогресії для імпульсного синуса $s i_{k}(t)$ :

$$
\sum_{a_{m}^{k} \in L \cup R}(-1)^{m-1} \times a_{m}^{k}=S_{k}\left(L R_{n}\right)_{,}
$$

де $L R_{n} \subseteq W$ часове вікно в області імпульсу досліджуваної функції в точці $\tau_{n}$, тобто в частковій сумі $S_{k}\left(L R_{n}\right)$ враховується вплив усіх імпульсів функції $s i_{k}(t)$, що потрапляють у вікно $L R_{n}$. Таким чином, рівняння балансу для однієї функції $s i_{k}(t)$ набуває вигляду:

$$
\beta_{k} \times \tau_{n}-S_{k}\left(L R_{n}\right)=0 .
$$

При підстановці значень для областей $L \mathrm{i}$ $R$ та перенесення всіх членів рівняння в ліву частину отримаємо такий вираз:

Однак, при формуванні результуючих імпульсів $r\left(\tau_{n}\right)$ бере участь множина імпульсних синусів $s i_{k}(t)$, які утворюють відповідну множину функцій $\Phi=\left\{s i_{k}(t)\right\}, k=\overline{1, K}$. Під час аналізу взаємовпливу імпульсних функцій в кожному вікні $L R_{n}$ має бути врахована ступінь впливу $x_{k} \in[0,1]-k$-ï функції імпульсного синуса на появу результуючого імпульсу $r\left(\tau_{n}\right)$. Як показали дослідження, за своєю логікою величина $x_{k}$ значною мірою визначається амплітудою синусоїдальної функції, що бере участь у формуванні результуючого часового ряду. Тоді в рівнянні балансу у вікні $L R_{n}$ доцільно врахувати для $k$-ї функції імпульсного синуса величину $x_{k} \in[0,1]$. Сумарний вплив функцій 3 множини $\Phi$ на 
формування результуючого імпульсу $r\left(\tau_{n}\right)$ в рівнянні балансу набуде вигляду:

$$
\sum_{k=1}^{K} x_{k} *\left\{\beta_{k} * \tau_{n}-S_{k}\left(L R_{n}\right)\right\}=0 .
$$

3 цього рівняння координата імпульсу $\tau_{n}$ результуючої імпульсної функції $r(t)$ визначатиметься співвідношенням:

$$
\tau_{n}=\left\{\sum_{k=1}^{K} x_{k} \cdot S_{k}\left(L R_{n}\right)\right\} \times\left\{\sum_{k=1}^{K} x_{k} \times \beta_{k}\right\}^{-1} .
$$

Наведене рівняння балансу в точці $\tau_{n} \epsilon$ однорідним лінійним рівнянням 3 невідомими коефіцієнтами $x_{k}$. Величина $\left\{\beta_{k} \times \tau_{n}-S_{k}\left(L R_{n}\right)\right\} \quad$ є нев'язкою, яка відповідає вкладу $k$-ї функції імпульсного синусу в результуючий імпульс $r\left(\tau_{n}\right)$ у відповідному вікні $L R_{n}$. Природно, чим більше ця невязка, тим менше вплив функції $s i_{k}(t)$ на формування імпульсу $r\left(\tau_{n}\right)$ i, відповідно, менше значення коефіцієнта $x_{k}$.

Знаходження коефіцієнтів $x_{k} \in[0,1]$ дає змогу визначити дискретну функцію виду $\omega_{n}(k): \Phi \rightarrow[0,1]$, де $\omega_{n}(k)=x_{k}$ у вікні $L R_{n} \subseteq W$. Ця функція $є$ аналогом розподілу миттєвої спектральної щільності сигналу [35], оскільки параметри імпульсних синусів $s i_{k}(t)$, чітко визначають частотно-фазові характеристики гармонійних сигналів, які породили результуючий часу ряд в тимчасовому вікні $L R_{n} \subseteq W$. У процесі узагальнення оцінок функцій $\omega_{n}(k)$ на всьому часовому просторі $\mathrm{W}$ можна отримати функцію $\omega(k): \Phi \rightarrow[0,1]$, яка $\epsilon$ аналогом загальної спектральної щільності досліджуваного сигналу.

Під час досліджень були отримані варіанти розв'язання задачі оцінки коефіцієнтів для спектрального розкладання довільного часового ряду.

1. Прямий метод оиінки коефіиієнтів спектрального розкладання. У випадку розгляду множини точок $\tau_{n,}, n=\overline{1, N}$ результуючої імпульсної функції $r(t)$ отримаємо систему однорідних лінійних рівнянь відносно значень коефіцієнтів $x_{k}$. Рішення цієї системи рівнянь при відомому обмеженні $N \geq K$ будь-яким 3 відомих методів [36] дає змогу визначити значення $x_{k}$, які утворюють функцію $\omega(k)$. Ця функція являє собою аналог спектральної щільності сигналу на інтервалі $\bigcup_{n=1}^{n=N} L R_{n} \subseteq W$.

Однак дослідження рішень отриманої системи однорідних лінійних рівнянь на практиці виявило проблему, пов'язану з тим, що при обмеженні $x_{k} \in[0,1]$ система рівнянь може не мати рішення. Ця ситуація $\epsilon$ неприйнятною для частотного аналізу часових рядів. Аналіз практичних ситуацій, коли система рівнянь не має рішення при обмеженнях на коефіцієнти $x_{k}$, пов'язана, перш за все, 3 тим, що існує вплив похибок дискретизації часового ряду i параметрів алгоритму ідентифікації метасістеми. Крім цього, для прямого розв'язання системи рівнянь необхідно виконання умови $N \geq K$. Цей факт не дає змоги чітко визначити миттєву спектральну щільність сигналу, що ускладнює частотно-часовий аналіз нестаціонарних часових рядів.

2. Метод оиінки коеріиієнтів спектрального розкладання на основі рішення задачі лінійного програмування. Для усунення зазначеного недоліку під час вирішення системи однорідних лінійних рівнянь у вікні $L R_{n} \subseteq W$ біля імпульсу $r\left(\tau_{n}\right)$ доцільно використовувати оптимізаційні підходи. Проте в якості обмеження доцільно використовувати нормуюче обмеження виду $\forall k, x_{k} \geq 0, \sum_{k=1}^{K} x_{k}=1$. Це обмеження враховує, що результуючий часовий ряд розглядається, як сума синусоїдальних функцій. Тоді функція $\omega_{n}(k): \Phi \rightarrow[0,1]$ буде являти собою умовний аналог нормованої миттєвої спектральної щільності в околі $\tau_{n}$ для досліджуваного часового ряду. 3 огляду на похибки в формуванні імпульсної функції $r(t)$, що представляє досліджуваний часовий ряд, оптимізаційна задача у вікні $L R_{n} \subseteq W$ може бути представлена у вигляді:

$$
\left\{\begin{array}{c}
\sum_{k=1}^{K} x_{k} \cdot\left\{\beta_{k} \cdot \tau_{n}-S_{k}\left(L R_{n}\right)\right\} \rightarrow \min _{\left\{x_{k}\right\}} \\
\sum_{k=1}^{K} x_{k}=1, \forall k, x_{k} \geq 0,
\end{array}\right.
$$

Оптимізація здійснюється за вектором змінних $\left\{x_{k}\right\}$, що визначають функцію $\omega_{n}(k)$, яка задає аналог миттєвого спектра у вікні $L R_{n} \subseteq W$. У системі нерівностей враховуються всі імпульсні синуси, які мають не порожню множину імпульсів у вікні $L R_{n}$. Ця задача $\epsilon$ класичною задачею лінійного програмування. Ї̈̈ 
розв’язання здійснюється відомими методами, наприклад, на основі симплекс-методу [37].

3. Наближена оиінка коефіцієнтів спектрального розкладання. Аналіз взаємодії імпульсних функцій і відповідного рівняння балансу показав ряд важливих особливостей.

1. Чим більше значення нев'язкі $\Lambda_{k}=\left\{\beta_{k} * \tau_{n}-S_{k}\left(L R_{n}\right)\right\}$, тим менше вплив відповідної функції $s i_{k}(t)$ на формування результуючого імпульсу у вікні $L R_{n} \subseteq W$.

2. Якщо нев'язка перевищує розміри вікна, то вплив відповідної функції $s i_{k}(t)$ на появу імпульсу $\mathrm{r}\left(\tau_{\mathrm{n}}\right)$ практично відсутній.

3. Збільшення розміру вікна $L R_{n} \subseteq W$ призводить до того, що кількість імпульсів функції $s i_{k}(t)$ у вікні може зростати, отже, нев'язка $\Lambda_{\mathrm{k}}$ теж може зростати.

4. Чим більше імпульсів функції $s i_{k}(t)$ потрапляє у вікно $L R_{n}$, тим менша вірогідність того, що ця функція визначає появу імпульсу $r\left(\tau_{n}\right)$. Як правило, якщо кількість імпульсів функції $s i_{k}(t)$ у вікні парне з рівною кількістю ліворуч і праворуч від $\tau_{n}$, то така функція не бере участі в породженні імпульсу $r\left(\tau_{n}\right)$.

3 цих результатів дослідження, можна сформувати наближену оцінку вектора змінних $\left\{x_{k}\right\}$. Нехай вікно визначається як замкнутий інтервал у вигляді $L R_{n}=\left[\tau_{n}-\varepsilon_{L}(n) ; \tau_{n}+\varepsilon_{R}(n)\right] \subseteq W$, де $\varepsilon_{L}(n), \varepsilon_{R}(n)$ - відхилення від координати імпульсу $\tau_{n}$ до лівої і правої межі вікна $L R_{n}$ відповідно. Розмір вікна визначатиметься величиною $\left(\varepsilon_{R}(n)+\varepsilon_{L}(n)\right)$. Тоді ступінь впливу функції $s i_{k}(t)$ на формування імпульсу у вікні $L R_{n}$ може бути оцінена величиною $\left[1-\frac{\llbracket \Lambda_{k} \rrbracket}{\left(s_{R}(n)+s_{L}(n)\right)}\right]$, де $\left|\Lambda_{k}\right|-$ абсолютне значення нев'язки. 3 урахуванням парності кількості імпульсів у вікні, а також можливості відсутності в цьому вікні імпульсів функції $s i_{k}(t)$, приблизна оцінка коефіцієнта $x_{k}$ У вікні $L R_{n}$ для відповідної імпульсної функції може бути визначена у вигляді функції:

$$
x_{k}=\left\{\begin{aligned}
\left|\beta_{k}\right| \cdot\left[1-\frac{\left|\Lambda_{k}\right|}{\left(\varepsilon_{R}(n)+\varepsilon_{L}(n)\right)}\right], & S_{k}\left(L R_{n}\right) \neq 0, \\
0, & S_{k}\left(L R_{n}\right)=0 .
\end{aligned}\right.
$$

4. Визначення вікна для формування рівняння балансу. Для всіх зазначених вище підходів одним $з$ важливих елементів алгоритму $\epsilon$ вибір розміру і форми вікна $L R_{n}$. Воно визначає коефіцієнти рівняння балансу у вигляді невязки $\Lambda_{k}$. Найприроднішим варіантом визначення вікна $L R_{n} \epsilon$ припущення, що кордони вікна лежать посередині координат сусідніх імпульсів. У цьому випадку $\varepsilon_{L}(n)=0.5 \cdot\left(\tau_{n}-\tau_{n-1}\right)$, $\varepsilon_{R}(n)=0.5 *\left(\tau_{n+1}-\tau_{n}\right)$. Тоді вікно $L R_{n}$ визначатиметься часовим відрізком у вигляді: $L R_{n}=\left[0.5 *\left(\tau_{n}-\tau_{n-1}\right) ; 0.5 *\left(\tau_{n+1}-\tau_{n}\right)\right]$.

$\mathrm{y}$ цьому випадку вікно $L R_{n}$ не $\epsilon$ балансу. Для усунення цього впливу може використовуватися симетричний варіант вікна $L R_{n}$. У цьому випадку апроксимація вікна може визначатися різними способами. Наприклад, як відхилення від координати $\tau_{n}$ може бути обраний варіант мінімального або максимального значення відхилення $\varepsilon(n)=\min \quad\left\{\varepsilon_{L}(n) ; \varepsilon_{R}(n)\right\}, \quad$ або $\varepsilon(n)=\max \left\{\varepsilon_{L}(n) ; \varepsilon_{R}(n)\right\}, \quad$ а також може бути використано усереднене значення відхилення, тобто $\varepsilon(n)=0.5 \cdot\left(\varepsilon_{L}(n)+\varepsilon_{R}(n)\right)$. В останньому випадку вікно буде мати вигляд:

симетричним відносно координати $\tau_{n}$, що може привести до додаткового спотворення рівняння

$$
L R_{n}=\left[\tau_{n}-0.25 \cdot\left(\tau_{n+1}-\tau_{n-1}\right) ; \tau_{n}+0.25 \times\left(\tau_{n+1}-\tau_{n-1}\right)\right] \subseteq W .
$$

Ці варіанти вікна доцільно використовувати в тому випадку, коли значення відхилення від координати $\tau_{n}$ не перевищує значення, визначеного залежністю $\varepsilon(n)<\min \left\{\left(\tau_{n}-\tau_{n-1}\right) ;\left(\tau_{n+1}-\tau_{n}\right)\right\}$.

Недослідженим залишається варіант, коли вікно $L R_{n}$ може мати непрямокутну форму, а визначатися деякої віконної функцією, як це прийнято, наприклад, у віконному перетворення Фур'є або в алгоритмах вейвлет-перетворень. У будь-якому випадку варіант вибору вікна впливає на отримане рішення і тому доцільно проведення надалі додаткових досліджень для оптимізації розміру і форми вікна $L R_{n}$.

5. Уточнення коефіиієнтів спектрального розкладання на основі алгоритмів нечіткої 
фільтраціiі. Через наявність похибок у визначенні значення функції $\omega_{n}(k): \Phi \rightarrow[0,1]$ умовної миттєвої спектральної щільності в околі $\tau_{n}$ для досліджуваного часового ряду доцільно розглянути варіант отримання оцінного значення цієї функції з урахуванням попередніх

$$
\widehat{\omega}_{n}(k)=\widehat{\omega}_{n-1}(k)+\alpha \cdot\{
$$

де $\omega_{n}(k)$ - функція умовної миттєвої спектральної щільності, яка розрахована за одним 3 наведених підходів, $\varphi_{n}^{R}(k)$ фільтруюча функція на просторі станів в околиці точки $\tau_{n}$. Вид цієї функції i iï параметри детально розглянуті в наведених вище роботах. $\alpha \in[0,1]$ - коефіцієнт посилення фільтру.

Оптимальне значення цього коефіцієнта може бути визначено відповідно до підходу, що описаний в [40].

Під час використання цих фільтрів поточні помилки визначення функції $\omega_{n}(k)$ можуть бути знижені. Спектральна картина для нестаціонарного часового ряду буде більше згладженої. Однак застосування підходів фільтрації, може знизити чутливість до різкої зміни поведінки часового ряду, що в деяких випадках $\epsilon$ неприйнятним. Тому алгоритми фільтрації доцільно застосовувати 3 урахуванням характеру реальної поведінки системи.

Висновки. Запропонований підхід у цілому дає змогу розв'язати задачу частотночасового аналізу нестаціонарних дискретних сигналів, які представляються часовими рядами. Простота розрахунків, які не потребують використання інтегрування функцій, суттєво спрощує підхід визначення частотних спектрів. У другій частині матеріалу буде наведено результати дослідження працездатності методу частотно-часового аналізу часових рядів на основі функцій поведінки і арифметичних рядів.

Перспективи подальших досліджень. Слід зазначити, що представлений матеріал доцільно розглядати як первинний, що задає напрями подальших досліджень. Як такі напрями слід розглядати частотно-часовий аналіз поведінки довільних систем, які описуються функціями поведінки. Якщо розглядати моменти зміни поведінки систем як деякі події, то предметом дослідження могли б бути аналіз і прогноз появи подій в динамічних системах. Це безпосередньо пов'язано, наприклад, із завданнями пошуку i прогнозу пошкодження технічних пристроїв. Цікавим $\epsilon$ дослідження застосування методу для задач частотної фільтрації сигналів, порівняння (кореляціï) сигналів в задачах розпізнавання образів тощо. Безумовно, дослідження запропонованого методу має бути продовжено точок $\tau_{j} j<n$. У цьому випадку задача може бути розв'язана на основі підходу нечіткої фільтрації, розглянутого в роботах [38, 39]. Як показано в цих роботах, оцінне значення функції $\widehat{\omega}_{n}(k)$ може бути розраховано на підставі залежності:

\section{$\left\{\left[\omega_{n}(k) \wedge \varphi_{n}^{R}(k)\right]-\widehat{\omega}_{n-1}(k)\right\}$,}

для виявлення його позитивних сторін і обмежень до застосування в задачах частотно-часового аналізу часових рядів.

\section{СПИСОК ВИКОРИСТАНОЇ ЛІТЕРАТУРИ}

1. Meffert B. Hochmuth O. Werkzeuge der Signalverarbeitung. Grundlagen, Anwendungsbeispiele, bungsaufgaben. 2. Auflage. Humboldt-Universitat zu Berlin, (2018). $-296 \mathrm{p}$

2. Lange F. H. Signale und Systeme. Band 3. Regellose Vorträge. Einführung in die Informationstheorie, Stochastik und Korrelationstechnik / F.H. Lange . - Berlin : VEB Verlag Technik, (1971) . - $391 \mathrm{p}$.

3. Unbehauen R.: Systemtheorie 1: Allgemeine Grundlagen, Signale und lineare Systeme im Zeit- und Frequenzbereich. Oldenbourg, (2002). $-583 \mathrm{p}$.

4. Сафиуллин Н. Т. Разработка методики анализа временных рядов с помощью преобразования ХуангаГильберта. Диссертация. ФГАОУ ВПО "Уральский федеральный университет имени первого Президента России Б. Н. Ельцина". Новосибирск, 2015. - 193 с.

5. Бокс Д., Дженкинс Г. Анализ временных рядов: прогноз и управление. М: МИР, 1974. - 406 с.

6. Daubechies, I. Orthonormal bases of compactly supported wavelets. Communications on pure and applied mathematics. XLI (1988) 7, p. 909-996.

7. Harmuth, H. F. Transmission of Information by Orthogonal Functions. New York: Springer-Verlag, 1969

8. J. Kova cevirc, V. K. Goyal, M. Vetterli. Fourier and Wavelet Signal Processing. (2013). - 272 p.

9. Beauchamp, K.G. Applications of Walsh and Related Functions. Orlando: Academic Press, (1984). - 308 p.

10. Heil C., Walnut D. Continuous and discrete wavelet transforms. SIAM Review, 31 (4), (1989). - P. 628-666

11. Rioul O., Duhamel P. Fast algorithms for discrete and continuous wavelet transforms. IEEE Trans. Inform. Th., sp. iss. Wavelet Transforms and Multiresolution Signal Analysis, (1992). - 38(2). - P. 569-586.

12. Радиотехнические цепи и сигналы. Задачи и задания: Учеб. пособие / В. Я. Баскей, В. Н. Васюков, Л. Г. Зотов, В. М. Меренков, В. П. Разинкин, А. Н. Яковлев/ Под ред. проф. А. Н. Яковлева. - Новосибирск: НГТУ, 2002. - 340 c.

13. Dickey D. A., Fuller W. A. Distribution of the Estimators for Autoregressive Time Series with a Unit Root / Journal of the American Statistical Association. - 74. (1979). - P. 427 431.

14. Kwiatkowski D., Phillips, P.; Schmidt, P., Shin, Y. Testing the null hypothesis of stationarity against the alternative of a unit root. Journal of Econometrics. (1992) 54 (1-3). - P. 159178.

15. Gabor D. Theory of communication // Journal IEE (London). (1946) Vol. 93. - P. 429-457.

16. Daubechies I. Orthonormal bases of compactly supported wavelets. //Commun. On Pure and Appl. (1998) Vol.41. - P. 909-996.

17. Dai G. Modal wave-front reconstruction with Zernike polynomials and Karhunen-Loeve functions, JOSA A, Vol 13, Issue 6, (1996). - P. 1218-1225

18. Коэн. Время-частотные распределения: Обзор // 
ТИИЭР. 1989. - Т. 77. № 10. - С. 72-120.

19. Mallat S. A Wavelet Tour of Signal Processing The Sparse Way. 3rd. Edition. Academic Press, Inc. Orlando, FL, USA (2008). - P. 851.

20. Кулаичев А. П. Критика вейвлет анализа ЭЭГ. Актуальные проблемы гуманитарных и естественных наук. № 12 (95) 2016. Ч.1 - С. 47-58.

21. Morlet J. Grossmann A. Sampling theory and wave propagation // Issues in Acoustic signal/Image processing and recognition. (1983) Vol. 1. - P. 233-261.

22. Christopher Torrence and Gilbert P. Compo. A Practical Guide to Wavelet Analysis // Bulletin of the American Meteorological Society. 1998. - V. 79. - P. 61.

23. Huang N. E. The Hilbert-Huang transform and its applications / Ed. By S.S.Shen. Interdisciplinary mathematical sciences. 5 Toh Tuck Link, Singapore 596224: World Scientiųc Publishing Company Co. Pte. Ltd. (2005). - P. 311.

24. Huang N. E., Shen Z., Long S. R. et al. The empirical mode decomposition and the Hilbert spectrum for nonlinear and non-stationary time series analysis // Proc. R. SOC. London, Ser. A. (1998) no. 454. - P. 903-995.

25. Wu Z., Huang N. E. Ensemble Empirical Mode Decomposition: a noise assisted data analysis method // Advances in Adaptive Data Analysis. (2008) Vol. 1, no. 1. P. $1-41$.

26. Klir G. Elias D. (1985) Architecture of Systems Problem Solving. New York, Plenum Press, 354 p.

27. Bocharnikov V., Bocharnikov I., Sveshnikov S Fundamentals of the systemic organizations management. Theory and Practice. LAP LAMBERT Academic Publishing, Berlin, 2012. - 296 p.

28. Бочарников В. П. Fuzzy-технология. Модальности и принятие решений при маркетинговых коммуникациях. Киев: Ника-центр, Эльга. 2002. - 224 с.

29. William A. Pearlman, Amir Said. Digital Signal Compression: Principles and Practice. - Cambridge
University Press, (2011). - P. 83

30. Hensel K. Untersuchung der Fundamentalglelchung einer Gattung fur eine reelle Prlmzahl als Modul und Bestimmung der Theiler Ihrer Discriminante // J. Reine Angew. Math. (1894), V. 113. - P. 61-83.

31. Каток С. Б. p-адический анализ в сравнении с вещественным / Пер. с англ. П. А. Колгушкина. М. МЦНМО, 2004. - 112 c.

32. Uyttenbove, H. J., Computer-aided systems modeling: An assemblage of methodological tools for systems problem solving. Ph.D. dissertation, School of Advanced Technology, SUNY-Binghamton, 1978.

33. Higashi M., Klir J. Measure of uncertainty and information based of possibility distribution. International Journal of General System, 9, No.1, 1983. - p. 43-58

34. Comstock F. Uyttenbove, H. J. A system approach to grading of flight symulator students. Journal of Aircraft, 16, No. 11,1979, - P. 780-786.

35. Коэн И. Время-частотные распределения: Обзор // ТИИЭР. Т. 77. № 10, 1989. - С. 72-120.

36. Лизунова Н. А., Шкроба С. П. Матрицы и системы линейных уравнений. - М.: ФИЗМАТЛИТ., 2007. - 352 с.

37. Borgwardt, Karl-Heinz. The simplex algorithm takes on average D steps for a cube. The simplex method: A probabilistic analysis. - Berlin: Springer-Verlag, 1987. - Vol. 1. - P. 268.

38. Bocharnikov V., Bocharnikov I. Discrete fuzzy filter of UAV's flight parameters. ISSN 1813-1166. Proceedings of the NAU. 2010. №3. - P. 30-39.

39. Bocharnikov V., Bocharnikov I. Simplified and adopted to the MatLab fuzzy filter of UAV's flight parameters. 2013 IEEE 2nd International Conference Actual Problems of Unmanned Air Vehicles Developments Proceedings. Kiev, Ukraine 15-17 October 2013. - P. 41-47

40. Bocharnikov V., Bocharnikov I. Optimal discrete fuzzy filter of UAV's flight parameters. ISSN 1813-1166. Proceedings of the NAU. 2012. №2. - P. 22-29.

Стаття надійшла до редакційної колегії 18.10.2018

\section{Бочарников В. П., Д.Т.н., профессор}

Центр военно-стратегических исследований Национального университета обороны Украины имени Ивана Черняховского, Киев;

\section{Частотно-временной анализ сигналов на основе функций поведения и арифметических рядов. Часть 1 . Анализ подходов, описание метода.}

Резюме. В статье предлагается новый подход частотно-временного анализа дискретных сигналов, которые представлены временными рядами. Для описания значений временного ряда используется базис p-адичних чисел, на основе которых строятся функции поведения системы. Анализ данных функций позволяет провести идентификацию метасистем и построить импульсные функции, формализуют временной ряд. Координаты импульсов описываются арифметическими рядами, которые используются для оценки частотного спектра сигнала.

Ключевые слова: временной ряд; частотно-временной анализ; $p$-адичные числа; функции поведения систем; системный анализ; идентификация; арифметические ряды; частотные спектры.

\section{Bocharnikov, DsT, professor}

Center for Military and Strategic Studies of the National Defence University of Ukraine named after Ivan Cherniakhovskyi, Kyiv

Time-frequency analysis of signals based on behavioral functions and arithmetic series. Part 1.

Resume. The article proposes a new approach for time-frequency analysis of discrete signals, which are represented by time series. To describe the values of the time series, the basis of p-adic numbers is used, on the basis of which the system behavior functions are built. The analysis of these functions allows the identification of metasystems and the construction of impulse functions that formalize the time series. The coordinates of the pulses are described by arithmetic series, which are used to estimate the frequency spectrum of the signal.

Keywords: time series; time-frequency analysis; p-adic numbers; system behavior functions; system analysis; identification; arithmetic series; frequency spectra. 